\title{
El "musicólogo transterrado". Los escritos etnomusicológicos de Baltasar Samper en México (1947-1964)
}

\author{
The "Exiled Musicologist". Baltasar Samper's \\ Ethnomusicological Writings in Mexico (1947-1964)
}

En este artículo presentamos una primera aproximación a un conjunto de textos hasta ahora desconocidos del músico y musicólogo catalán exiliado Baltasar Samper, responsable, desde 1947 y hasta su muerte, de dirigir los trabajos etnomusicológicos de la Sección de Investigaciones Musicales del Instituto Nacional de Bellas Artes mexicano. Con esto queremos mostrar la influencia de Samper en la dirección y desarrollo de una primera etnomusicología positivista en el contexto posrevolucionario mexicano, y cómo lo hizo a partir de la relectura y traslación en México de su propia experiencia etnomusicológica en Cataluña y Baleares con la Obra del Cançoner Popular de Catalunya en las décadas de 1920 y 1930.

Palabras clave: exilio, transtierro, etnomusicología, nacionalismo, positivismo.

This article is the first to examine a series of previously unknown texts by the exiled Catalan composer and musicologist Baltasar Samper. Samper was responsible for supervising ethnomusicological studies in the Music Research Section at the Instituto Nacional de Bellas Artes in Mexico from 1947 until his death. The article aims to demonstrate Samper's influence on the direction and evolution of early positivist ethnomusicology in the context of post-revolutionary Mexico, and how he re-interpreted and transferred his own ethnomusicological experience in Catalonia and the Balearic Islands with the Obra del Cançoner Popular de Catalunya in the 1920s and 1930s to Mexico.

Keywords: exile, transtierro, ethnomusicology, nationalism, positivism

En verano de 2017 pasé dos meses y medio en México con el propósito de estudiar la figura de Baltasar Samper (1888-1966), conocido músico y musicólogo catalán nacido en Mallorca que se exilió a Francia en 1939 y llegó al país americano en 1942. Localicé su fondo personal, que se presuponía de un gran valor, en manos de uno de sus nietos ${ }^{1}$. Gracias a ello, pude consultar, inventariar

\footnotetext{
${ }^{1}$ A partir de lo que el pianista mallorquín Joan Moll vio y anotó sobre su corto encuentro en el año 1989 con la viuda de Samper, Dolors Porta. Joan Moll: "Conversa d'en Joan Moll amb na Dolors Porta", X Simpòsium i Jornades Internacionals de l'Orgue Històric de les Balears / Trobada de Documentalistes Musicals, Palma, Fundació ACA, 2003, pp. 123-125.
} 
y dar a conocer este extraordinario legado musical, básicamente partituras, que pronto va a permitir obtener, finalmente, un completo retrato musical de este maestro del Noucentisme catalán y de la República²

Asimismo, otro de los focos principales de mi atención en México era el Archivo Histórico del Centro Nacional de Investigación, Documentación e Información Musical Carlos Chávez (CENIDIM), entidad que desde 1974 sustituye a la antigua Sección de Investigaciones Musicales (SIM) del Departamento de Música del Instituto Nacional de Bellas Artes (INBA). Actualmente el CENIDIM se encuentra en el complejo del Centro Nacional de las Artes (CENART) de la Ciudad de México. La SIM, a su vez, fue la continuadora de las tareas de otra Sección de Investigaciones Musicales, la del Departamento de Música de la Secretaría de Educación Pública (SEP) que dirigía el músico Luis Sandi (1905-1996) y que había empezado a funcionar en la década de 1920. Baltasar Samper entró a trabajar en la SEP a principios de $1945^{3}$ y desde aquel año hasta su muerte en 1966 trabajó en las sucesivas SIM como jefe responsable del desarrollo de lo que entonces se entendía como "estudios de folklore".

Ese mismo año 1945 había sido invitado por el folkloristaVicente T. Mendoza a dar una conferencia en la Sociedad Folklórica de México sobre la Obra del Cançoner Popular de Catalunya (OCPC), proyecto en el que trabajó en Cataluña y Baleares desde 1924 hasta 1936. . Sin duda, Samper era conocido dentro del mundo musicológico por sus trabajos en esta entidad, de la que llegó a ser secretario y uno de sus misioneros más destacados y prolíficos; un colector de materiales orales con una "capacidad excepcional"" Fue un observador especialmente perspicaz de los cantos de trabajo de Mallorca, tema del que presentó una comunicación en el III Congreso Internacional de Musicología que se celebró en Barcelona del 18 al 24 de abril de 19367. Toda esta

\footnotetext{
${ }^{2}$ Amadeu Corbera Jaume: "Baltasar Samper, compositor: el redescobriment d'un compositor català a l'exili", Revista Catalana de Musicologia, 11, 2018, pp. 199-231. En el artículo se adjunta inventario del fondo musical de Samper.

${ }^{3}$ Así lo cuenta en varias cartas. Carta de Baltasar Samper a Josep Valls, 12-1-1946. Barcelona, Biblioteca de Catalunya, fondo Josep Valls i Royo, Top. Jva1251; Carta de Baltasar Samper a Joan M. Thomàs, 12-1-1948. Palma, Partituroteca de la UIB, caja 4, fondo Joan M. Thomàs.

${ }^{4}$ Yael Bitrán Goren: "La investigación musical: la experiencia mexicana", Perspectivas y desafios de la investigación musical en Iberoamérica, Yael Bitrán Goren, Cynthia Rodríguez Leija (coords.), Ciudad de México, Secretaría de Cultura / Instituto Nacional de Bellas Artes, 2016, pp. 129-144.

${ }^{5}$ Baltasar Samper: "La investigación folklórica en la 'Obra del cancionero popular de Cataluña", Anuario de la Sociedad Folklórica de México 1945, 6, 1949, pp. 213-232.

'Jaume Ayats: "La 'cançó popular' (1830-2000)", Història Crítica de la Música Catalana, Francesc Bonastre, Francesc Cortès (eds.), Barcelona, Servei de Publicacions de la Universitat Autònoma de Barcelona, 2009 , p. 344.

${ }^{7}$ Josep Martí: "Etnomusicologia catalana: entre la literatura, la musicologia i l'antropologia", AIXA. Revista del Museu Etnologgic del Montseny, 4, 1991, pp. 19-34.
} 
trayectoria y experiencia, así como la metodología de trabajo de la OCPC, la compartió de una manera muy detallada y extensa en la mencionada conferencia.

\section{La Obra del Cançoner Popular de Catalunya (OCPC)}

La OCPC había sido instituida en 1922 por el empresario y mecenas catalán, y de profundas convicciones catalanistas, Rafael Patxot i Jubert (18721964), en colaboración con el Orfeó Català. El proyecto nació en el apogeo del Noucentisme, en un contexto de efervescencia nacionalista en Cataluña, con el propósito de reunir un gran corpus de la música popular de todos los territorios de habla catalana. La diferencia de la OCPC respecto a otras iniciativas anteriores era, además de su gran magnitud inicial, el enfoque positivista y comparativista de las misiones, y la adopción de una metodología de recolección y trabajo de campo, con unas normas muy claras que debían subscribir todos los colaboradores ${ }^{8}$.

Baltasar Samper,junto a su amigo Miquel Ferrà, poeta también mallorquín, fue quien redactó esas normas en el verano de $1924^{9}$. Entre muchas otras indicaciones, se recomendaba el uso del fonógrafo, del que era un firme partidario - mientras que algunos misioneros se mostraban reacios a usarlo ${ }^{10}$, , y sacar una fotografia de los cantores o intérpretes, además de la obligatoriedad de llevar un diario de campo donde registrar no solo las melodías y canciones, sino también las "impresiones personales o emotivas durante la Misión"11. Como señala Jaume Ayats, estas "orientaciones metodológicas [...] contenían, pues, muchos de los elementos de la musicología comparada contemporánea y de la investigación etnográfica" 12 , y sitúan la Obra del Cançoner en un plano de modernidad científica todavía poco habitual para la época.

Sin embargo, la mayoría de los misioneros, a pesar de las instrucciones, mantuvieron un perfil más bien esencialista y de idealización de la canción popular. No fue exactamente así en el caso de Baltasar Samper, encargado, por su origen, de la exploración de las Islas Baleares. Hemos mencionado su interés por las canciones de trabajo de Mallorca: Samper convirtió este tipo de cantos en

\footnotetext{
${ }^{8}$ J. Ayats: "La 'cançó popular'...", pp. 343-344.

"Josep Massot i Muntaner: "Introducció", Baltasar Samper. Estudis sobre la cançó popular, Josep Massot i Muntaner (ed.), Barcelona, Publicacions de l'Abadia de Montserrat, 1994, pp. 5-25.

${ }^{10}$ Por ejemplo, Higini Anglès, otro de los destacados musicólogos catalanes que trabajó en la OCPC, opinaba que "el pes feixuc del fonògraf constituia una impedimenta destorbadora [el peso engorroso del fonógrafo constituía un equipaje molesto] para las misiones”. Josep Massot i Muntaner (ed.): Obra del Cançoner Popular de Catalunya. Materials. 5. Història de l'Obra del Cançoner i complement a l'inventari de l'arxiu, Barcelona, Publicacions de l'Abadia de Montserrat, 1995, p. 265.

${ }^{11}$ J. Massot i Muntaner: "Introducció", p. 13: "llurs impressions personals o emotives durant la Missió".

${ }^{12}$ J. Ayats: "La 'cançó popular'...", p. 344: "[Les] orientacions metodològiques [...] contenien, doncs, molts dels elements de la musicologia comparada contemporània i de la recerca etnogràfica".
} 
su objeto de estudio principal. Observó como los campesinos eran incapaces de articular ninguna canción de este tipo sin recrear o hacer el gesto del trabajo en cuestión -labrar, segar, trillar, etc.-:

La primera observación que [...] se puede hacer en Mallorca, respecto de estos cantos de trabajo, es el hecho del íntimo vínculo que existe entre ellos y los trabajos particulares a los que corresponden. Los payeses mallorquines la sienten tan naturalmente, esta relación, que no sabrían considerar el canto como algo extraño al trabajo, como algo accidental de lo cual se pueda prescindir en un momento dado, sino que para ellos es algo consustancial al mismo trabajo, un elemento del todo inseparable - un elemento, diríamos, orgánico- ${ }^{13}$.

Baltasar Samper estableció, pues, una relación clara entre el hecho musical (cantar) y el acto social (el trabajo).Y aunque es dificil hablar de etnomusicología en los términos actuales en las décadas de 1920 y 1930, en conjunto, sus trabajos muestran un dominio metodológico y una capacidad analítica de las estructuras sociales del objeto de estudio musical fuera de lo común y nos permite reconocerlo, salvando las distancias, como un precursor de la etnomusicología catalana -y española por extensión-.

Todavía sin un modelo sobre el que apoyarse y de manera intuitiva, pues carecía de formación antropológica, Samper se anticipaba a su tiempo y se acercaba al paradigma culturalista que, por aquellos años, George Herzog ya estaba desarrollando en los Estados Unidos, paradigma que daría paso al nacimiento de la etnomusicología como disciplina diferenciada, pero que en los Países Catalanes y en España no se consolidaría hasta las últimas décadas del siglo $\mathrm{XX}^{14}$.

\section{La investigación musical en la Secretaría de Educación Pública (SEP)}

El primer texto etnomusicológico de Baltasar Samper en México y sobre México se publicó en 1947 en la revista Nuestra Música-revista que daría lugar a la editorial Ediciones Mexicanas de Música-, editada por el grupo de compositores del mismo nombre con Rodolfo Halffter y Carlos Chávez como figuras principales, además de Adolfo Salazar, Jesús Bal y Gay y los mexicanos Blas Galindo, José Pablo Moncayo y Luis Sandi' ${ }^{15}$.

\footnotetext{
${ }^{13}$ Baltasar Samper: "Les cançons de treball agrícoles a Mallorca", Baltasar Samper. Estudis..., p. 36: "La primera observació que [...] hom pot fer a Mallorca, respecte d'aquests cants de treball, és el fet de l'íntim lligam que existeix entre ells i els treballs particulars a què corresponen. Els pagesos mallorquins la senten tan naturalment, aquesta relació, que no sabrien considerar el cant com una cosa estranya a la feina, com una cosa accidental de la qual hom pugui prescindir en un moment donat, sinó que per a ells és quelcom substancial amb la mateixa feina, un element del tot inseparable -un element, diríem, orgànic-".

${ }^{14}$ Josep Martí: "Folk Music Studies and Ethnomusicology in Spain", Yearbook for Traditional Music, 29, 1997, pp. 107-140.

${ }^{15}$ Consuelo Carredano: Ediciones Mexicanas de Música: historia y catálogo, México, CENIDIM Carlos Chávez, 1994.
} 
En el artículo, titulado "La investigación musical en el departamento de música de la SEP”, Samper explica la creación de la Sección de Investigación Musical de la SEP a principios de 1946 por iniciativa de Sandi,"con el objeto de dar un nuevo y mayor impulso a los trabajos de recopilación, estudio y publicación del folklore musical mexicano, como también los de exploración de nuestros archivos" ${ }^{\prime 16}$. Ese impulso pasaba por reorientar la recopilación de material folklórico realizada hasta la fecha en México hacia una metodología mucho más sistemática y positivista: "Se imponía, sin embargo, a todos los que aquí se enfrentan con los problemas de nuestra cultura musical, la necesidad de intensificar las actividades aludidas y de encauzarlas en una labor metódica favorecida por todos los medios requeridos por las técnicas del día" ${ }^{17}$.

También se detallan los planes de la nueva Sección que, como explicó Antonio Ruiz ${ }^{18}$, copian la metodología y el plan de trabajo que Samper había aprendido en la OCPC, pero incorporando los avances tecnológicos de los años 40 y toda su experiencia anterior: adquisición de colecciones folklóricas existentes, la convocatoria de un concurso y expediciones con un mínimo de dos personas con conocimientos musicales y lingüísticos provistas de un equipo de grabación y fotográfico, para obtener un documento lo más fiel y objetivo posible.También la obligatoriedad de llevar un diario de la expedición:

El material que deberán entregar los investigadores al regreso de cada expedición comprenderá: discos grabados, anotaciones originales de los documentos recogidos al dictado y copias en limpio y numeradas de todos estos documentos; películas cinematográficas de las danzas y de los aspectos de fiestas populares o ceremonias que ofrezcan algún interés folklórico; fotografias de todas las personas que hayan comunicado documentos [...], de los lugares visitados, habitaciones, indumentaria, cultivos, utensilios de trabajo, instalaciones de industrias tradicionales, instrumentos musicales, y en general de todo aquello que pueda aportar algún dato de interés $\left[\ldots\right.$. . Además será anotado un Diario de la expedición $[\ldots]^{19}$.

Cabe destacar la importancia que Baltasar Samper daba al uso de la tecnología de grabación, que a mediados de los años 40 ya era bastante mejor que la que disponía cuando empezó en 1924. Hasta ese momento, parece que las grabaciones de música popular en las expediciones que se habían organizado desde la SEP eran algo más bien ocasional ${ }^{20}$. Samper, en cambio, traza un plan de trabajo que no solo pasa por una entera renovación metodológica, sino

${ }^{16}$ Baltasar Samper: "La investigación musical en el departamento de música de la SEP", Nuestra Música, 2, 5, 1947, p. 39 .

${ }^{17}$ Ibid., p. 40

${ }^{18}$ Antonio Ruiz Caballero: Tras las huellas de Baltasar Samper: influencia de un músico e investigador catalán en la investigación musical mexicana, memoria de investigación inédita, Barcelona, Institut d'Estudis Catalans, 2015.

${ }^{19}$ B. Samper: "La investigación musical...", pp. 40-41.

${ }^{20}$ Y. Bitrán Goren: "La investigación musical...”, pp. 129-144. 
también por la formación de personal de acuerdo con los nuevos parámetros. Tal formación se dio en las Prácticas de Investigación Folklórica que él mismo impartió en el Conservatorio Nacional ${ }^{21}$ :

Con el fin de disponer de suficiente personal especializado [...] fue inaugurada en el Conservatorio Nacional y en la Academia de Folklore de dicho plantel una clase especializada de Prácticas de investigación folklórica que tiene por objeto la formación de un grupo de investigadores que puedan hacerse cargo en breve y con las necesarias garantías de éxito, de la recopilación musical de las misiones que les sean confiadas ${ }^{22}$.

Este plan de trabajo también contaba con la necesidad de ordenar todo lo recogido hasta la fecha en el Archivo de Folklore de la SEP y la edición de todos los materiales folklóricos ${ }^{23}$. Al mismo tiempo, una expedición ya estaba en marcha desde julio de aquel año en el Valle de Mezquital con los grupos otomíes. Samper también menciona que se habían empezado a explorar diferentes archivos y se estaba trabajando "en el Convento del Carmen de San Ángel, hoy Villa Obregón, y se procede a la copia de interesantes composiciones polifónicas halladas en el archivo de esta institución"24.

Al crearse el Instituto Nacional de Bellas Artes (INBA) en 1947, los trabajos de la SEP fueron integrados en la nueva institución y Samper fue nombrado jefe de la Subsección de Folklore de la nueva Sección de Investigaciones Musicales del Departamento de Música del INBA ${ }^{25}$. Será aquí donde desarrollará la mayor parte de su plan de trabajo previamente esbozado, aunque con cada vez más dificultades presupuestarias, de medios y de personal. Es al poner en marcha la Sección de Investigaciones Musicales (SIM) cuando Samper contrata e instruye como trabajador de campo a Raúl Hellmer ${ }^{26}$, quien actualmente es considerado como uno de los investigadores más importantes de la música popular mexicana del siglo $\mathrm{XX}^{27}$.

${ }^{21}$ Carta de Baltasar Samper a Josep Valls, 24-3-1946, Barcelona, Biblioteca de Catalunya, fondo Josep Valls i Royo, Top. Jval251.

${ }^{22}$ B. Samper: "La investigación musical...", p. 42.

${ }^{23}$ Publicaciones que no llegaron hasta 1962 y 1964. Baltasar Samper (ed.): Investigación Folklórica en México. Materiales. Volumen I, Ciudad de México, Instituto Nacional de Bellas Artes, 1962; — (ed.): Investigación Folklórica en México. Materiales. Volumen II, Ciudad de México, Instituto Nacional de Bellas Artes (INBA), 1964.

${ }^{24}$ B. Samper: "La investigación musical...", p. 42.

${ }^{25}$ Informe de labores desarrolladas entre el 1 de agosto de 1947 y el 30 de junio de 1948 por la Sección de Investigaciones Musicales. Ciudad de México, Archivo Histórico del CENIDIM, exp. 159. Citado también por A. Ruiz Caballero: Tras las huellas..., p. 23.

${ }^{26}$ Comunicaciones entre Baltasar Samper y Raúl Hellmer. Ciudad de México, Archivo Histórico del CENIDIM, exp. 936.

${ }^{27}$ Y. Bitrán Goren: "La investigación musical...", p. 131. 
Primero como responsable en la SEP, más tarde en el INBA como jefe de la Subsección de Folklore y, a partir de 1964, ya como director de toda la SIM, Baltasar Samper llegó a trabajar prácticamente 21 años como etnomusicólogo en México, hasta pocos días antes de morir. Eso sin olvidar las clases en el Conservatorio Nacional: la citada asignatura impartida en 1946, y otra vez en 1961, ya con mayores conocimientos sobre la música popular del país, como profesor de la cátedra de Folklore Musical de México ${ }^{28}$.

$\mathrm{Su}$ liderazgo metodológico influyó notablemente en sus colegas. Además de Hellmer,Virginia Rodríguez, cofundadora junto a Mendoza de la Sociedad Folklórica de México, se inspiró claramente en la OCPC para desarrollar sus trabajos de recopilación, y su propuesta de encuesta de investigación ${ }^{29}$ es la misma que la planteada por Samper en su conferencia de $1945^{30}$ (cuadro 1).

Cuadro 1. Modelo de encuestas de Baltasar Samper y Virginia Rodríguez

\begin{tabular}{|c|c|}
\hline $\begin{array}{c}\text { Encuesta de Baltasar Samper } \\
\text { en la OCPC (1945) }\end{array}$ & $\begin{array}{c}\text { Encuesta de Virginia Rodríguez } \\
\text { en México (1953) }\end{array}$ \\
\hline $\begin{array}{l}\text { 1. Lugar y fecha en que el documento es } \\
\text { recogido. } \\
\text { 2. Nombre completo -y apodo, en su caso- } \\
\text { del comunicante. Su sexo, edad y lugar de } \\
\text { nacimiento. Su ascendencia. Si ha vivido } \\
\text { siempre en el lugar en que se encuentra o } \\
\text { ha cambiado de residencia. Si ha viajado o } \\
\text { ha permanecido en un mismo lugar. } \\
\text { 3. De quién, cuándo y dónde aprendió la } \\
\text { versión que comunica. } \\
\text { 4. Origen o autor del documento, cuando } \\
\text { sea conocido. } \\
\text { 5. Ocasión particular, en su caso, en que se } \\
\text { canta o ejecuta. } \\
\text { 6. Quién lo canta o ejecuta. } \\
\text { 7. Instrumentos, si los hay. } \\
\text { 8. Observaciones adicionales, si son pertinen- } \\
\text { tes. }\end{array}$ & $\begin{array}{l}\text { 1. Lugar y fecha en que se recoge. } \\
\text { 2. Nombre completo del comunicante, apo- } \\
\text { do, en caso de tenerlo, sexo, edad, lugar de } \\
\text { su nacimiento; nombres de sus padres y } \\
\text { sitio de origen. Si ha residido siempre en la } \\
\text { población, y si ha viajado, por qué lugares } \\
\text { y en qué fechas más o menos. } \\
\text { 3. De quién y dónde aprendió la versión que } \\
\text { comunica, y en qué fecha. } \\
\text { 4. Origen o autor del documento, si lo tiene. } \\
\text { 5. Ocasión particular en que tiene lugar el } \\
\text { hecho. } \\
\text { 6. Si se trata de documentos musicales: quién } \\
\text { o quiénes cantan o ejecutan. } \\
\text { 7. Instrumentos con que se acompaña, si los } \\
\text { hay. } \\
\text { 8. Observaciones adicionales que sean perti- } \\
\text { nentes en cada caso. }\end{array}$ \\
\hline
\end{tabular}

${ }^{28}$ Hoja informativa del Conservatorio Nacional de México. Barcelona, Biblioteca del Pabellón de la República de la Universidad de Barcelona, Fondo FP, subserie Miquel Ferrer, sig. FP (Ferrer) 1.2.2 (Exili 1939-1980).

${ }^{29}$ Virginia Rodríguez Rivera: "La investigación folklórica en el campo. Mis experiencias", Aportaciones a la investigación folklórica de México, Ciudad de México, Sociedad Folklórica de México, 1953, p. 41

${ }^{30}$ B. Samper: "La investigación folklórica...", p. 225. 
Sin embargo, a pesar de tantos años de trabajo y del reconocimiento explícito de coetáneos como Vicente T. Mendoza -"el investigador de música popular mexicana más destacado de su generación”, según Gerard Béhague $^{31}$-, la labor desarrollada por Baltasar Samper en México es todavía hoy poco conocida y aún menos estudiada, incluso muchas veces son directamente ignorados su papel y responsabilidades en la formación de la etnomusicología moderna en el país americano. Queda muy lejos de la popularidad de otros investigadores y recopiladores mexicanos como Vicente T. Mendoza, Gabriel Saldívar, Thomas Standford, Henrietta Yurchenco, Carmen Sordo o, sobre todo, Raúl Hellmer ${ }^{32}$. A modo de ejemplo, ni Béhague ${ }^{33}$ ni Steven Loza ${ }^{34}$ mencionan de ninguna manera las actividades de Samper en la SIM; tampoco lo hace Marina Alonso Bolaños ${ }^{35}$. Gabriel Pareyón, por otra parte, le dedica una brevísima y muy escueta entrada en su Diccionario ${ }^{36}$, mucho menor que, sin ir más lejos, la de su buen amigo y compañero de trabajo Jesús Bal y Gay ${ }^{37}$.

\section{El musicólogo transterrado}

En el Archivo Histórico del CENIDIM se conserva una cantidad muy abundante de material documental de la SIM y de la SEP, que van desde oficios administrativos a informes varios, apuntes manuscritos, diarios de campo, fotos y hasta un diario de trabajo personal de Baltasar Samper. Es en este archivo donde encontramos las conferencias, inéditas hasta ahora, que Samper dio en 1951 y 1964, y que complementan así otros textos etnomusicológicos suyos que ya habían sido dados a conocer: los estudiados por Josep Massot sobre la $\mathrm{OCPC}^{38}$ y las conferencias en la Sociedad de Folklore comentadas por Antonio Ruiz ${ }^{39}$, además del artículo en Nuestra Música.

${ }^{31}$ Gerard Béhague: "Latin America”, Ethnomusicology. Historical and Regional Studies, Helen Myers (ed.), Nueva York, W.W. Norton \& Company, 1993, p. 473: "Mexico's foremost folk music scholar of his generation".

32 Rosa Virginia Sánchez: "La etnomusicología en el CENIDIM a través de los años: una breve revisión", Cuarenta años de investigación musicológica en México a través del CENIDIM, Yael Bitrán Goren, Luis Antonio Gómez, José Luis Navarro (coords.), Ciudad de México, Instituto Nacional de Bellas Artes, 2016, pp. 149-168.

${ }^{33}$ G. Béhague: "Latin America", pp. 472-494.

34 Steven Loza: "Contemporary Ethnomusicology in Mexico", Latin American Music Review / Revista de Música Latinoamericana, 11, 2, 1990, pp. 201-250.

${ }^{35}$ Marina Alonso Bolaños: La "invención” de la música indígena de México, Buenos Aires, Editorial SB, 2008.

${ }^{36}$ Gabriel Pareyón: Diccionario Enciclopédico de Música en México, Zapopan, Universidad Panamericana, 2007, p. 941.

${ }^{37}$ G. Pareyón: Diccionario Enciclopédico..., p. 104.

${ }^{38}$ J. Massot (ed.): Baltasar Samper. Estudis..., p. 86-110.

${ }^{39}$ A. Ruiz: Tras las huellas..., p. 29-32. 
Parece ser que Samper llegó a México con la intención inicial de seguir con su carrera de compositor y director de orquesta. Así lo hace constar explícitamente en todos los documentos migratorios (archivos de la Junta de Auxilio a los Republicanos Españoles, JARE, y la ficha de migración mexicana), y así se desprende también de sus $\operatorname{cartas}^{40}$. Pero fue en el desarrollo de esta primeriza y embrionaria etnomusicología, tanto en la SEP como después en el INBA, donde encontró la manera de reproducir en el exilio lo que ya había ensayado previamente en Cataluña: "He tenido la alegría de copiar nuestra organización de Barcelona [la OCPC]. Le envío por separado una 'cédula', calcada a las nuestras", le explicó a su amigo y antiguo jefe Rafael Patxot ${ }^{41}$.

Sin entrar en las causas que le llevaron por un camino y no por otro, ese trasplante metodológico y paradigmático de la OCPC a la SIM, y la seria voluntad de desarrollo de la etnomusicología en México que muestra Samper, nos remite a la idea de "transterrado" que acuñó uno de los ilustres exiliados españoles, el filósofo José Gaos, para describir el sentimiento de los republicanos al llegar al México posrevolucionario y nacionalista del presidente Lázaro Cárdenas:

Los refugiados, que habían sido unos inadaptados en España, que por ello habían querido reemplazar por otra a la que estuviesen adaptados, se encontraron con un México muy afín a la España con la que habían querido reemplazar la otra - un Estado liberal promotor de bienestar y progreso con justicia social- y al que por tanto eran más adaptables que a esta última ${ }^{42}$.

Así, el transterrado de Gaos construye una doble identidad hispano-mexicana, no solo por la afinidad cultural, sino también por la afinidad de las propuestas políticas republicana española y posrevolucionaria mexicana. ¿Es este el caso de Baltasar Samper? Ciertamente, los proyectos de la OCPC en la Cataluña de los años 20 y de la SIM en el México posrevolucionario de los años 40 comparten la pulsión nacionalista y reformista de renovación cultural y construcción nacional a partir de lo tradicional, en el caso catalán, o lo indígena, en

\footnotetext{
${ }^{40}$ Samper escribe: "pienso vengarme este año del trabajo industrial [la música de cine] terminando un Cuarteto que tengo empezado [...] y escribiendo un Concierto para violoncelo, que era ya mi ilusión cuando todavía vivía en Francia" ["penso revenjar-me aquest any del treball industrial acabant un Quartet que tinc començat [... ] i escrivint un Concerto per a violoncel, que ja era la meva il.lusió quan encara vivia a França."]. Carta autobiográfica de Baltasar Samper enviada a Josep Valls, 12-1-1947, Barcelona, Biblioteca de Catalunya, fondo Josep Valls i Royo, top. Jval251. En esa misma carta, explica que los funcionarios de la SEP le ofrecieron el trabajo "sobre el Folklore mexicano", que finalmente aceptó; "iEl Folklore me persigue siempre impecablemente!" ["el Folklore em persegueix sempre implacablement!"], resumía con algo de resignación.

${ }^{41}$ Carta de Baltasar Samper a Rafael Patxot, 7-6-1949: "He tingut el goig de copiar la nostra organització de Barcelona. Li envio per separat una 'cèdula', calcada a les nostres". Josep Massot: "Baltasar Samper, de l'Obra del Cançoner a França i a Mèxic”, Randa, 82, 2019, pp. 82-83.

42 José Gaos: Filosofía mexicana de nuestros días, México, Imprenta universitaria, 1954, p. 316, citado en José Luis Abellán: El exilio como constante y como categoría, Madrid, Biblioteca Nueva, 2001, p. 94.
} 
el caso mexicano ${ }^{43}$.A pesar de esto, es dificil hablar de Samper -el personaje, el artista o el intelectual- como un transterrado absoluto en los términos hispánicos de Gaos. Como apunta Mari Paz Balibrea, el exilio catalán responde a otro paradigma diferente del español, ya que "los catalanes no tenían la misma relación con la cultura española en el Nuevo Mundo" 44 . Dentro de este marco, y dada su militancia en el republicanismo catalán, se entiende que Pilar Ramos piense que "Baltasar Samper [...] probablemente se consideraba catalán a secas, no español" ${ }^{45}$; no sabemos si es por este motivo o porque Samper se dedica a la etnomusicología más que al campo de la historia -o por ambos- que lo deja fuera de su estudio de la musicología española en el exilio.

Baltasar Samper, ciertamente, militó en organizaciones catalanistas de exiliados y tuvo en ellas un papel destacado ${ }^{46}$, aunque siempre echó de menos volver a Cataluña y a Mallorca ${ }^{47}$. Balibrea señala que, en el caso de muchos exiliados catalanes, y el de Samper parece paradigmático en este aspecto, ese efecto de desarraigo y el contacto "con culturas autóctonas les despojó de todo sentido de correspondencia entre su identidad y el medio ambiente. De esta manera entraron en plena posesión de su exilio" ${ }^{48}$. En el caso concreto de la labor musicológica, no obstante, Baltasar Samper sí parece adquirir un compromiso, una dedicación y hasta una doble identidad musicológica con México que no muestra en otros aspectos políticos, nacionales o incluso artísticos. En este sentido, su trayectoria musicológica es claramente una continuidad, parafraseando a Pilar Ramos ${ }^{49}$, con su etapa anterior en Cataluña, no solo por la oportunidad que se le brinda de liderar los trabajos etnomusicológicos del INBA con la metodología de la OCPC, que tan buen rendimiento y reconocimiento le había dado, sino que asume los resultados y las investigaciones con auténtico interés nacional:

${ }^{43}$ Marina Alonso Bolaños: La "invención”..., p. 53.

${ }^{44}$ Mari Paz Balibrea: "Otros paradigmas del exilio republicano", Lineas de fuga. Hacia otra historiografía cultural del exilio republicano español, Mari Paz Balibrea (coord.), Madrid, Siglo XXI, 2017, p. 96.

${ }^{45}$ Pilar Ramos López: "Musicología española y exilio: continuidades y rupturas", Discursos y prácticas musicales nacionalistas (1900-1970), Pilar Ramos López (ed.), Logroño, Servicio de Publicaciones de la Universidad de La Rioja, 2012, p. 116.

${ }^{46}$ Sin ir más lejos, y por citar un ejemplo, Samper, que estaba afiliado al partido Acció Catalana desde 1930, fue presidente de la Comunitat Catalana de Mèxic entre 1944 y 1946, entidad que aglutinaba todos los partidos catalanistas en el exilio, y representante por ella en el Consell Nacional de Catalunya -una suerte de gobierno independiente catalán en el exilio creado después del asesinato del presidente de la Generalitat, Lluís Companys-. Daniel Díaz Esculías: El catalanisme polític a l’exili, Barcelona, La Magrana, 1991.

${ }^{47}$ En una de sus últimas cartas, Samper escribe: "Si aún estuviera a tiempo de volver a Europa -cosa poco probable- ciertamente, no iría a Barcelona: iría a Mallorca y moriría más feliz" ["Si encara fos a temps de tornar a Europa -cosa poc probable- certament, no aniria a Barcelona: aniria a Mallorca i moriria més content"]. Carta de Baltasar Samper a Joan M. Thomàs, 27-10-1961, Palma, Partituroteca de la UIB, fondo documental Joan Maria Thomàs, caja 4.

${ }^{48}$ M. P. Balibrea: "Otros paradigmas...", p. 96.

${ }^{49}$ P. Ramos: "Musicología española...", pp. 115-139. 
Podemos confiar en que las autoridades futuras que han de regir el pueblo mexicano se percatarán de la importancia de esta clase de trabajos por medio de los cuales toma el país conciencia de sí mismo, de su historia y de su realidad presente, tan diferente de lo que muestran otras culturas y tan propiamente mexicana, puede decirse. Si, junto al porvenir de estos estudios, se consigue llevar a término los trabajos de Musicología histórica respecto a la música culta de nuestro país, [...] México podría ufanarse de sus hombres de estudio y de unos medios de gobierno que permiten realizarlos $[\ldots]^{50}$.

Sea como sea, este proceso es indisociable, como señalan autores como David Kettler o Antolín Sánchez Cuervo, de la dimensión política de Baltasar Samper en cuanto que exiliado, "incluso en su pura existencia pasiva" 51 , y como su persistencia, también la de sus proyectos es o puede ser leída como un acto político de resistencia permanente ${ }^{52}$.

\section{Las conferencias de la Sección de Investigaciones Musicales (SIM) en 1951}

Con estos textos se nos presenta un corpus etnomusicológico de Baltasar Samper en México y sobre México mucho más amplio de lo que hasta ahora conocíamos. El primer grupo forma parte de dos ciclos de conferencias que Samper impartió en verano y otoño de 1951 para presentar los resultados de los trabajos de la SIM. El primero de estos tuvo lugar en la sala Manuel Ponce del Palacio de Bellas Artes ${ }^{53}$ y estuvo a cargo de los dos responsables de la Sección, Baltasar Samper y Jesús Bal y Gay. Fueron varias conferencias en seis sesiones, dos de Bal y Gay y cuatro de Samper. El orden y título de las sesiones coincide en gran parte con el índice del primer volumen de Investigación Folklórica en México. Materiales, de 1962; también algunos de los textos coinciden. A diferencia de sus escritos sobre su trabajo en la OCPC, aquí Samper no habla a partir de una experiencia propia, sino que se convierte en portavoz o narrador de las experiencias de otras personas en misiones de años atrás o las de Raúl Hellmer en curso, a quien él dirige y planifica el trabajo.

\footnotetext{
${ }^{50}$ Extracto, en media hoja suelta, de los apuntes de una de las conferencias -no sabemos cuál- de Samper de noviembre de 1951. Conferencias sobre la música folklórica mexicana para la Academia de Capacitación de la Secretaría de Hacienda y Crédito Público, Ciudad de México, Archivo Histórico del CENIDIM, exp. 900.

${ }^{51}$ Antolín Sánchez Cuervo: "El exilio como figura política", Líneas de fuga. Hacia otra historiografía del exilio republicano español, Mari Paz Balibrea (coord.), Madrid, Siglo XXI, 2017, p. 191

52 David Kettler: "Spiritual Diaspora and Political Exile", Journal of the Interdisciplinary Crossroads, 1, 2, 2004, pp. 269-282.

${ }^{53}$ Invitación a una serie de conferencias de la SIM en el Palacio de Bellas Artes. Ciudad de México, Archivo Histórico del CENIDIM, exp. 219.
} 
Así, en este expediente encontramos el borrador de parte de la penúltima de las conferencias -solamente una hoja y media- con la descripción de los carnavales de Tepoztlán que había hecho el investigador Francisco Domínguez en 1933, y que fue publicada en el mencionado volumen de $1962^{54}$. De la otra conferencia, la última del ciclo, titulada "Investigación en curso entre grupos de lengua nahua, empezada en 1947 en el Estado de Morelos", encontramos dos borradores parciales. Los dos están llenos de apuntes manuscritos, partes borradas y rayadas, y son de un contenido parecido, con ligeras diferencias. Estos materiales nunca llegaron a ser publicados.

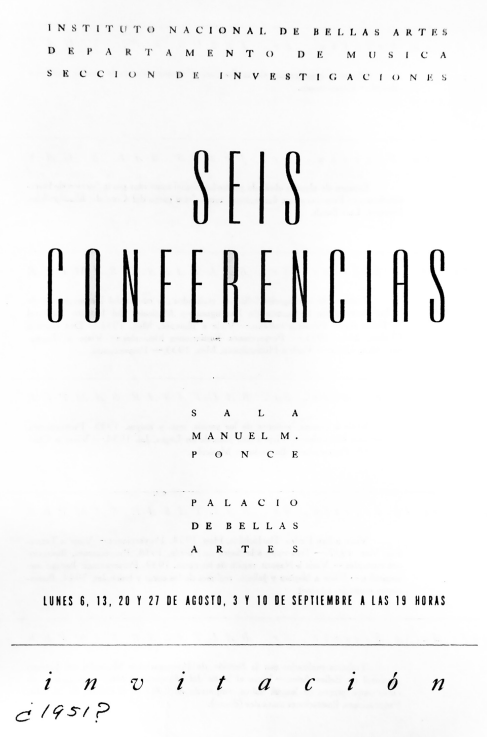

a)

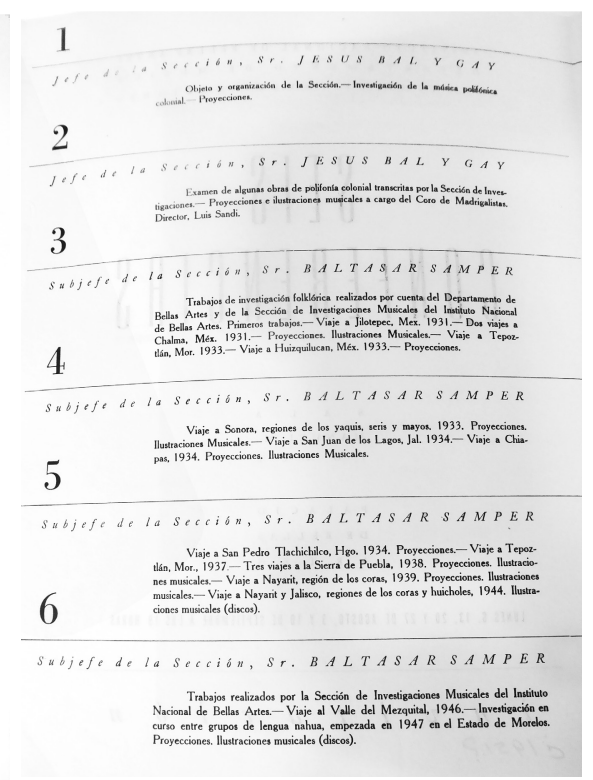

b)

Ilustración 1. Portada (a) y programa (b) de las seis conferencias de Baltasar Samper y Jesús Bal y Gay en verano y otoño de 1951. Ciudad de México, Archivo Histórico del CENIDIM, exp. 219

En el primero, titulado de manera algo imprecisa "Investigación en curso en diversos lugares", Samper explica que al crearse la SIM en el INBA, se iniciaron las investigaciones sobre los grupos nahua (o náhuatl) del Estado de Morelos, "una de las zonas del país menos exploradas" y "relativamente próxima" a la Ciudad de México. Se encargó a Raúl Hellmer los trabajos de exploración por

${ }^{54}$ Francisco Domínguez: "Investigación folclórico musical realizada en Tepoztlán, Estado de Morelos, en febrero de 1933, por Francisco Domínguez", Investigación folklórica en México. Materiales. Volumen I, Baltasar Samper (ed.), Ciudad de México, Instituto Nacional de Bellas Artes, 1962, pp. 85-98. 
Morelos "y la parte sur de Puebla", siguiendo las normas dictadas para las misiones de la SIM. En esta conferencia en concreto, el etnomusicólogo catalán cuenta las vicisitudes del investigador por las zonas de Cuautla y Tepoztlán, sus problemas técnicos, las dificultades para relacionarse con la población, etc. Llega a calificar el trabajo de "en extremo penoso" por las dificultades de transporte. Según se lee, la música tradicional de los pueblos nahua en esta área ya se estaba perdiendo. Sobre la región de Cuautla comenta:"el canto es a veces tan rudimentario que podría sospecharse que los informantes lo improvisan, si no fuera por la persistencia de ciertas fórmulas que hacen pensar en la existencia de un estilo, muy simple, pero estilo al fin". En Tepoztlán el problema fue que Hellmer no fue capaz de relacionarse fácilmente con la población, mientras que en las primeras exploraciones en el noroeste del Estado de Puebla ya se habían registrado algunos huapangos "de gran valor".

Sorprende la honestidad de Samper al confesar que "en la región que nos ocupamos [Morelos], la recolección no ha recompensado los esfuerzos que han sido necesarios para obtenerla". "Sin embargo", concede, "considerada en su conjunto proporciona un valioso material para el estudio, pues da una idea exacta del estado en que se halla el repertorio tradicional en la extensa zona explorada".

El otro borrador, mucho más largo y con más detalles de los trabajos, se titula, de manera más concreta, "Investigación en curso entre grupos de lengua nahua". Cabe suponer que se acercaba más a la conferencia final. Aquí Samper es más profundo, como lo es al hablar de las fórmulas de estilo de canto nahua en Morelos, a las que añade una pequeña descripción melódica: "descenso de la voz, de un sonido agudo a otro grave, en el ámbito de una octava y con terminación a la dominante", aclara.

Sobre las causas de la desaparición de la tradición musical nahua en general, Baltasar Samper no duda que, aparte del impacto de la Revolución Mexicana en su momento, la culpa es de la "acción corrosiva de las influencias modernas, que en todas partes está destruyendo el patrimonio musical”. Este punto de vista, más bien esencialista, parece ser propio del Samper exiliado. En otro texto de 1952 dedicado a los cantos de trabajo de Mallorca, aparecido en la revista catalana del exilio Pont Blau, también apunta a la misma cuestión de la siguiente manera:"La gente mayor aún recordaba las canciones de la tierra, aprendidas antes que los discos, la radio y las máquinas infernales instaladas en las tabernas y los salones de baile emprendiesen la bárbara invasión que fácilmente cumplía su obra" ${ }^{55}$.

${ }^{55}$ Publicado en los números 2 y 3-4 de Pont Blau, octubre y noviembre-diciembre de 1952. Recogido en J. Massot i Muntaner: Baltasar Samper. Estudis..., p. 66: "La gent vella prou recordava encara les cançons de la terra, apreses abans que els discos, la ràdio i les màquines infernals instal.lades a les tavernes i a les sales de ball emprenguessin la bàrbara invasió que fàcilment acomplia la seva obra". 
Pero estas quejas contrastan con el Samper trabajador de la OCPC, mucho más aséptico en sus comentarios sobre las transformaciones de los hábitos culturales, en este caso, de la sociedad mallorquina de los años de 1920:

Entre las canciones anotadas está la tan conocida "Un pobre pagès", cuya melodía presenta una curiosa modificación. La cantan lentamente y con una gran expresión. Preguntamos de dónde saben esta canción y nos dice Tomeu que la aprendió de oírla en un fonógrafo del café [...]. Es la segunda vez que nos encontramos con un caso como este. El fonógrafo propagando las canciones populares ${ }^{56}$.

Volviendo a las conferencias, otro expediente contiene las leídas aquel mismo año, en este caso dentro del curioso - por temática y contexto- ciclo de conferencias "Usted y el fisco" organizado por la Academia de Capacitación de la Secretaría de Hacienda y Crédito Público en noviembre de $1951^{57}$, también en el Palacio de Bellas Artes.

No obstante, en el expediente encontramos mezclados textos de las conferencias de agosto y septiembre. En el primero de todos, fechado el 20 de agosto, Samper anuncia que hablará de "unos trabajos llevados a cabo el año 1931" por la SEP, los primeros de los que ha podido reunir toda la información. A continuación, resume las actividades de recogida de materiales folklóricos desde las primeras misiones en el año 1922 hasta la fecha, con especial énfasis en el cambio metodológico que él mismo, al hacerse cargo de la SIM -primero en la SEP y luego en el INBA- había ordenado:

A fin de unificar el trabajo de los colectores en los aspectos técnicos del mismo, fueron redactadas unas normas en las que se procuró condensar las recomendaciones que, sin menospreciar la iniciativa personal del investigador, ayudaran a asegurar la aplicación de procedimientos metódicos que permitieran obtener una documentación con todos los requisitos deseables ${ }^{58}$.

Toda esta presentación precede de la crónica de estos trabajos, llevados a cabo por Francisco Domínguez. Son fragmentos de las dos memorias recuperadas por Samper de los archivos de la SEP y publicadas - aunque algo más

\footnotetext{
${ }^{56}$ Baltasar Samper: "Memòria de la missió de recerca de cançons i músiques populars realitzada per Baltasar Samper i Ramon Morey a Mallorca, Eivissa i Formentera del 7 d'agost al 27 de setembre de 1928, per comanda de l'Obra del Cançoner Popular de Catalunya", Obra del Cançoner Popular de Catalunya. Materials, vol. X. Memòries de missions de recerca per Baltasar Samper; Palmira Jaquetti, Josep Massot i Muntnaer (ed.), Barcelona, Publicacions de l'Abadia de Montserrat, 2000, p. 17: "Entre les cançons anotades hi ha la tan coneguda 'Un pobre pagès', la melodia de la qual ofereix una curiosa modificació. La canten lentament i amb una gran expressió. Preguntem d'on saben aquesta cançó i ens diu en Tomeu que la va aprendre de sentir-la a un fonògraf del cafè [...]. És la segona vegada que ens trobem amb un cas com aquest. El fonògraf propagant les cançons populars".

${ }^{57}$ Conferencias sobre la música folklórica mexicana para la Academia de Capacitación de la Secretaría de Hacienda y Crédito Público, Ciudad de México, Archivo Histórico del CENIDIM, exp. 900.

${ }^{58}$ Texto n. ${ }^{\circ}$ 1, 20-8-1951, p. 3. Conferencias sobre la música folklórica mexicana para la Academia de Capacitación de la Secretaría de Hacienda y Crédito Público, Ciudad de México, Archivo Histórico del CENIDIM, exp. 900.
} 
cortas y con pequeños cambios- en el volumen de 1962, sobre el carnaval de los xhitas de Jilotepec y la peregrinación del santuario de Chalma. Además, encontramos en el mismo expediente el resumen de la expedición de Domínguez a Sonora, a las regiones de los pueblos yaquis, seris y mayos de 1933; el de la expedición a Chiapas junto a Luis Sandi en 1934 en los pueblos de los chamulas, zinacatecos y lacandones, y varios apuntes de las tres expediciones de Roberto Téllez Girón por la Sierra de Puebla en 1938. Las memorias de todas estas expediciones fueron publicadas y se pueden leer en el volumen editado en $1962^{59}$.

Los otros textos del expediente sí se corresponden con el ciclo de conferencias de la Academia de Capacitación. Encontramos una vez más resúmenes y explicaciones de las citadas expediciones de Domínguez y Sandi de 1933 y 1934, así como la de Roberto Téllez Girón en el Estado de Nayarit entre los cora (1939) -misión que ocupó todo el segundo volumen de Investigación folklórica en México de 1964-,junto con la descripción de la Fiesta del Peyote de Henrietta Yurchenco, de su misión entre los huicholes de Jalisco en $1944^{60}$. Pero también encontramos la conferencia inaugural del 6 de noviembre de 1961 que es, esta sí, una aportación enteramente original del mismo Baltasar Samper.

En este texto además de anunciar el contenido de las conferencias que se van a desarrollar, Samper comenta brevemente las crónicas de Francisco Domínguez en la Isla Tiburón -hogar de los seris-, de 1933, y de José Puig Gurí en la selva lacandona para una expedición del INBA en $1949^{61}$, en la que probablemente podemos leer una de las primeras descripciones conocidas del ritual de la "canción del jaguar" 62 -aunque para Puig es la "canción del tigre"de los lacandones:

Entonces, la actitud de los lacandones tuvo todo el encanto de un ritual pagano. Sus voces surgieron, alrededor de la hoguera, con tanta dulzura, tan evocadoras e impregnadas al mismo tiempo de miedo y de superstición, que hacían olvidar que

\footnotetext{
${ }^{59}$ B. Samper (ed.): Investigación Folklórica en México. Materiales. Volumen I.

${ }^{60}$ Este material nunca fue editado por Samper, sino que se publicó años más tarde. Véase Henrietta Yurchenco: "Investigación folclórico musical en Nayarit y Jalisco. Grupos indígenas coras y huicholes", Música y danzas del gran Nayar, Jesús Jáuregui (ed.), Ciudad de México, Centro de Estudios Mexicanos y Contemporáneos, 1993, pp. 141-170.

${ }^{61}$ José, o Josep, Puig Gurí era otro exiliado catalán, médico traumatólogo y cirujano. En 1949 formó parte de la expedición del INBA a la selva lacandona, en el Estado de Chiapas, junto a Carlos Frey, descubridor de las ruinas mayas de Bonampak. Raúl Anguiano: Expedición a Bonampak. Diario de un viaje. Memorias de una expedición a la Selva Lacandona, 1949, Tuxla, Universidad de Ciencias y Artes de Chiapas, 2012.

${ }^{62}$ Sobre la "canción del jaguar", véase la primigenia descripción de Phillip y Mary Baer: "The Lacandon Song of the Jaguar", Tlalocan, 2, 4, 1948, p. 376. Este trabajo fue ampliado y revisitado por Nicholas Hopkins: "The Lacandón Song of the Jaguar", Tlalocan, 15, 2008, pp. 111-113, http://dx.doi.org/10.19130/iifl. tlalocan.2008.184 (consulta 26-12-2020).
} 
la fiera estaba a pocos metros de nosotros [...]; y aquel canto en la oscuridad, en la soledad de la selva, tembloroso por el terror, rondados por el feroz visitante, causaba a un tiempo gozo a los sentidos y pavor.

¡Era la canción del tigre ${ }^{63}$ !

Otra vez encontramos aquí un Samper con un discurso con marcados tintes esencialistas y evolucionistas, a diferencia del etnomusicólogo catalán de mirada crítica y positivista de antes del exilio.Así, utiliza los términos "pureza" y "contaminación" para referirse a la "música india", o compara la actividad musical de los pueblos seri y lacandón con las de "el hombre primitivo en las más remotas edades". Escribe:"La función de la música en estas comunidades que por razón de aislamiento no han alcanzado más que un grado muy inferior de cultura, es esencialmente mágica [...]. Naturalmente, el canto está asociado a las prácticas religiosas de estos modernos primitivos $[\ldots]$ ".

Centrándonos en este aspecto del que ya hemos señalado varios ejemplos, ¿a qué se debe este cambio? Pilar Ramos apunta, con razón, que en las publicaciones de Samper sobre la OCPC en México "más que la nostalgia pesa más la compulsión nacionalista por la hipérbole" ${ }^{64}$. Podría ser también que hubiese asumido enteramente la misma "compulsión nacionalista" del México posrevolucionario -y la visión del indígena que se tenía en aquel contexto ${ }^{65}$-; o simplemente, en el último ejemplo, se podría tratar de un caso de adecuación ante un auditorio que presuponemos no familiarizado con la materia, pero sí con una idea preconcebida y ampliamente extendida entonces de "lo indígena".

Parece, pues, que Samper, como musicólogo transterrado en el contexto posrevolucionario mexicano, y una vez asumidos los que para él eran los nuevos valores y convencionalismos de su entorno laboral, académico y social, quisiera o sintiera la necesidad de (re)observar su trayectoria musicológica anterior desde este nuevo punto de vista, proyectando la experiencia de su presente sobre su propio trabajo anterior.

Volviendo a los textos, hay todavía otra referencia interesante a la Danza delVenado de los yaquis - mito presente también en los pueblos mayo y huichol-, ritual que despertó considerable interés entre los dos investigadores que trabajaron sobre el terreno en su momento, Francisco Domínguez $^{66}$ y Henrietta Yurchenco ${ }^{67}$. También era interesante, pues, para Baltasar

${ }^{63}$ B. Samper: "La música de los indios seris de Sonora. Música recogida en la sierra de Puebla", 6-111951 , p. 3. Conferencias sobre la música folklórica mexicana para la Academia de Capacitación de la Secretaría de Hacienda y Crédito Público, Ciudad de México, Archivo Histórico del CENIDIM, exp. 900.

${ }^{64}$ P. Ramos: "Musicología española...", p. 121.

${ }^{65}$ M. Alonso Bolaños: La “invención”. .

${ }^{66}$ Francisco Domínguez: "Informe sobre la investigación folklórico-musical realizada en las regiones de los yaquis, seris y mayos, Estado de Sonora, entre abril y mayo de 1933", Investigación folklórica en México. Materiales. Volumen I, Baltasar Samper (ed.), Ciudad de México, Instituto Nacional de Bellas Artes, 1962, pp. 113-226.

${ }^{67}$ Henrietta Yurchenco: “Grabación de música indígena”, Nuestra Música, 1, 1946, pp. 65-79. 
Samper: "La Danza del Venado" explica, "es sin duda el documento más importante entre todos los que la tradición oral ha conservado entre los yaquis", que eran, junto a los yumas de Arizona, Estados Unidos, los pueblos de la región fronteriza que seguían practicando este ritual ${ }^{68}$.

Aunque no la cite, esta comparación de los yaquis con los yumas nos remite al trabajo de la etnomusicóloga estadunidense Frances Densmore, Yuman and Yaqui Music, publicado por la Smithsonian Institution en 1932, y que es posible que hubiera leído ${ }^{69}$. Otra referencia, esa sí mencionada por Samper, es la del noruego Carlos, o Carl, Lumholtz, El México desconocido, obra que en 1904 el gobierno mexicano había mandado traducir al castellano y publicar debido a su interés ${ }^{70}$.

Pero Baltasar Samper obtiene la mayor parte de su información, sin decirlo, de la crónica de las misiones de Henrietta Yurchenco entre los yaquis (no toda, ya que algunos fragmentos son de la expedición de Domínguez). De esta crónica, todavía sin publicar, Samper cuenta de manera muy breve, aunque con algunos preciosos detalles, cómo la danza es la representación de una larga historia: "La narración se refiere principalmente a un gran viaje, maravilloso y lleno de incidentes, que realiza el Venado. Durante este viaje muestra el poder mágico que tiene sobre otros animales, el [sic] mismo se transforma y pone nombre a ríos y montañas".Y prosigue:

Otros cantos envuelven el poder delVenado en una poesía delicada y sutil. Por ejemplo:"Después de haber estado durante largo tiempo en las tinieblas, elVenado le dijo a la araña que le hiciera un camino en la oscuridad. La araña hizo el camino y ahora el Venado está viajando por él. El camino hecho por la araña era un largo hilo de su propia tela. El Venado lo siguió hasta que salió de las tinieblas"”11.

Estas conferencias iban acompañadas de proyecciones y grabaciones de música, que Samper había seleccionado y anotado cuidadosamente.

\section{La conferencia del Congreso Nacional de Música de 1964}

Para el otoño 1964 se convocó el IV Congreso Nacional de Música de México, que se celebró en el Conservatorio Nacional entre los días 28 de septiembre y 2 de octubre. Baltasar Samper intervino como "Jefe" (aparece rayado en el original) de la SIM del Departamento de Música del INBA.

${ }^{68}$ B. Samper: "La música de los indios yaquis y mayos, de Sonora", s. f., p. 7. Conferencias sobre la música folklórica mexicana para la Academia de Capacitación de la Secretaría de Hacienda y Crédito Público, Ciudad de México, Archivo Histórico del CENIDIM, exp. 900.

${ }^{69}$ Francis Densmore: Yuman and Yaqui Music, Washington, Smithsonian Institution, Bureau of American Ethnology, 1932.

${ }^{70}$ Carlos Lumholtz: El México desconocido. Cinco años de exploración entre las tribus de Sierra Madre occidental; en la Tierra Caliente de Tepic y Jalisco, y entre los tarascos de Michoacán, Nueva York, Charles Scribner's Sons, 1904.

${ }^{71}$ B. Samper: "La música de los indios yaquis...", p. 9. 
La conferencia la encontramos en el Archivo Gerónimo Baqueiro Fóster, con el título de "Problemas de la investigación folklórica en México"72. Samper empieza comentando sus dudas, por primera vez, acerca del uso de los términos "folklore" y "folklórico": "[...] porque no encuentro una palabra que, por un lado, debería abarcar todos los aspectos de la materia objeto de nuestro trabajo de investigación y, por otro lado, excluir los que dejamos fuera de este campo". El viejo musicólogo ponía en cuestión las limitaciones del paradigma folklorístico con el que había trabajado toda su vida, puede que consciente del cambio conceptual que desde unos años antes impulsaban académicos como Alan Merriam y Mantle Hood en los EUA ${ }^{73}$, y que empezaba a hacerse un hueco en el mundo latinoamericano: justo en 1963 se había celebrado la Primera Conferencia Interamericana de Etnomusicología en Colombia, con ponencias de Hood y Charles Seeger, pero sin ninguna participación mexicana ${ }^{74}$.

Por otro lado, la comunicación de este Congreso de 1964 se centra en los problemas logísticos, más que ideológicos o metodológicos, de la investigación etnomusicológica en el México de los años 1940-1960:

Las dificultades que se presentan al investigador aquí no difieren mucho de las que ordinariamente se encontrarán en todas partes para la realización de trabajos de esta índole [...]. Por ejemplo: hay zonas montañosas, muy alejadas de la capital, que interesa explorar. Se puede llegar a sus inmediaciones por ferrocarril o carretera, pero para internarse en ellas $[\ldots]$ se han de recorrer grandes distancias en la montaña, a caballo y a pie por caminos de herradura y por veredas apenas trazadas $[\ldots]^{75}$.

Samper también da algunos datos de las expediciones de Henrietta Yurchenco -aunque sin mencionarla- entre los huicholes (1944) y tarahumaras (1946), y las de los lacandones de Sandi y Domínguez (1933) y de José Puig con Carlos Frey en Bonampak (1949), en la que se describe, como ya comentamos, la escena de la "canción del tigre" o del jaguar.

Pese a los problemas económicos que afrontaba la SIM y a los cada vez más migrados recursos e interés por parte del gobierno, Samper termina con una mirada menos esencialista y, de algún modo, también menos alarmista que en los discursos anteriores. Justifica el interés de la SIM durante todos estos años por la "investigación de grupos indígenas" por encima de la música "de carácter general", ante la desaparición de expresiones musicales

${ }^{72}$ Baltasar Samper: "Problemas de la investigación folklórica en México", Ciudad de México, Biblioteca de las Artes del CENART, Archivo Gerónimo Baqueiro Fóster, exp. 4334.

${ }^{73}$ Helen Meyers: "Ethnomusicology", Ethnomusicology. An Introduction, Helen Myers (ed.), Nueva York, W. W. Norton \& Company, pp. 3-18.

${ }^{74}$ María-Ester Grebe: "Primera Conferencia Interamericana de Etnomusicología, Cartagena de Indias, Colombia, 24-28 de Febrero, 1963. Trabajos Presentados", Journal of the International Folk Music Council, 19, 1967, pp. 142-144.

${ }^{75}$ B. Samper: "Problemas de la investigación folklórica en México", p. 1. 
por la transformación de la forma de vida de los pueblos mencionados, que "[...] aunque no abandonen del todo sus tradiciones, no podrán preservarlas de influencias inevitables; y al transformarse su género de vida, se transformarán y se eliminarán usos que ya no podrán tener aplicación"76.

\section{Conclusiones}

Baltasar Samper dirigió las instituciones oficiales de investigación y recolección de música popular mexicana desde 1945 hasta su muerte en 1966. Lo hizo avalado por el prestigio adquirido con sus trabajos en la Obra del Cançoner Popular de Catalunya. Avanzado a su tiempo, Samper introdujo en México el enfoque positivista y una metodología muy precisa y sistemática para la recolección etnográfica musical, copia de la de la OCPC.Y, como hemos visto, influyó notablemente en sus coetáneos.

A pesar de haber dirigido los trabajos de investigación de la SIM del INBA durante 21 años y de su clara influencia en el nacimiento de la etnomusicología mexicana, el legado investigador de Baltasar Samper en México sigue siendo poco conocido o ignorado.

Ahora podemos mirar con más detalle este legado intelectual, así como ver su proceso de adaptación al nuevo contexto, y al menos en la faceta investigadora, Baltasar Samper aparece como una suerte de "musicólogo transterrado", partiendo de la idea de José Gaos. Este proceso, por otra parte, y en el caso concreto de Samper, parece ir también en una doble dirección espacio-temporal, donde él mismo observa su pasado investigador a partir de los nuevos paradigmas de su nuevo entorno intelectual, cultural y político, en un sentido mucho más esencialista, determinista y de "hipérbole nacionalista" que en su época de la OCPC. También en esta línea la de Samper representa, al contrario de lo que en un primer momento se pudo pensar, una voluntad casi total de persistencia y continuidad en el exilio de la etnomusicología catalana al menos en el plano metodológico.

Todo esto nos da una mayor perspectiva de Baltasar Samper como etnomusicólogo y de su influencia posterior tanto en los Páses Catalanes como en México.Aunque la dimensión e impacto de sus trabajos en Cataluña y México son diferentes -también para él lo fueron-, la reconstrucción del camino intelectual de Samper no puede eludir ninguno de los dos ámbitos.

Por otra parte, cabe preguntarse el porqué del ostracismo al que Baltasar Samper ha sido sometido contemporáneamente en México, obviando su papel, liderazgo e influencia en la consolidación de la primera etapa de la etnomusicología mexicana moderna. En Cataluña ocurre lo contrario. Su faceta

\footnotetext{
${ }^{76}$ Ibid., p. 7.
} 
etnomusicológica es bien conocida y reconocida actualmente, muy por encima de sus otras dedicaciones como compositor, crítico, pianista o director de orquesta.

Como hemos expuesto, como catalán, la experiencia exílica de Baltasar Samper fue, más allá de lo estrictamente profesional, diferente de la de los refugiados españoles. Al final de su vida, Samper parece como si hubiese terminado en una especie de triple exilio o triple experiencia de desarraigo y un triple olvido posterior: mallorquín entre los catalanes, catalán entre los españoles, y español entre los mexicanos. Eso enlaza con como Edward Said define la condición del exiliado: "un estado discontinuo del ser" "77. La triple condición de desposesión es, por lo tanto, un hecho de discontinuidad todavía mayor. Si en el caso de Robert Gerhard, amigo de Baltasar Samper y exiliado en Inglaterra, Germán Gan se pregunta a quién corresponde encargarse de su legado histórico ${ }^{78}$, a los ingleses o a los catalanes, en el caso de Samper esta cuestión es aún más dificil de responder.

Así, al morir Baltasar Samper en febrero de 1966, el médico andaluz Miguel Prado quiso informar del triste suceso al amigo común y antiguo compañero Jesús Bal y Gay con unas palabras que ahora y a la luz de todo lo expuesto, nos son sumamente reveladoras: "[...] él tuvo hasta el fin esa maravillosa y casi inútil responsabilidad por los destinos de la investigación musical en México. No le interesaban ya las cosas europeas, solamente las de aquí le preocupaban. ¿Fue mexicano, fue español? Es idiota preguntarlo. Fue una persona dignísima [...]"79. Poco más se puede añadir.

En 1994 se publicaron los textos etnomusicológicos de Baltasar Samper sobre sus trabajos de la OCPC. Eso sumado a la publicación de sus diarios de campo y materiales recogidos en Baleares entre los años 1924 y 1932, lo situó como una de las figuras destacadas de una primera etnomusicología catalana y española de los inicios del siglo XX. Ahora, una posible edición detallada y crítica de los textos que aquí damos a conocer, y que se añaden a los hasta ahora conocidos de su etapa mexicana, acabaría de completar la visión general y necesaria del etnomusicólogo catalán, su experiencia y la persistencia de su proyecto en el exilio en su doble dimensión profesional y política. Todo junto debería al menos terminar con el olvido histórico del legado etnomusicológico de Samper en México, permitir juzgar su papel en el desarrollo de la disciplina con nueva información y completar satisfactoriamente, también, la memoria etnomusicológica mexicana del siglo XX.

${ }^{77}$ Edward Said: Reflections on Exile and Other Literary and Cultural Essays, Londres, Granta Books, 2012, p. 177: "a discontinuous state of being".

${ }^{78}$ Germán Gan Quesada: "La recepció de la música de Robert Gerhard a Catalunya durant el franquisme (1948-1970): trobades i desavinences", Revista Catalana de Musicologia, 7, 2014, pp. 153-171.

${ }^{79}$ Carta de Miguel Prados a Jesús Bal y Gay, 20-2-1966, Madrid, Residencia de Estudiantes-CSIC, fondo Jesús Bal y Gay, sig. 280790340/BAL/2/199/2. 


\section{Bibliografía}

Abellán, José Luis: El exilio como constante y como categor $\square$ a, Madrid, Biblioteca Nueva, 2001. Alonso Bolaños, Marina: La "invención” de la música indígena de México, Buenos Aires, Editorial SB, 2008.

Anguiano, Raúl: Expedición a Bonampak. Diario de un viaje. Memorias de una expedición a la Selva Lacandona, 1949, Tuxla, Universidad de Ciencias y Artes de Chiapas, 2012.

Ayats, Jaume: "La 'cançó popular' (1830-2000)”, Història Crítica de la Música Catalana, Francesc Bonastre, Francesc Cortès (eds.), Barcelona, Servei de Publicacions de la Universitat Autolnoma de Barcelona, 2009, pp. 327-354.

Baer, Phillip; Baer, Mary: “The Lacandon Song of the Jaguar”, Tlalocan, 2, 4, 1948, p. 376.

Balibrea, Mari Paz: "Otros paradigmas del exilio republicano”, Líneas de fuga. Hacia otra historiografía cultural del exilio republicano español, Mari Paz Balibrea (coord.), Madrid, Siglo XXI, 2017, pp. 87-135.

BéHague, Gerard: "Latin America”, Ethnomusicology. Historical and Regional Studies, Helen Myers (ed.), Nueva York, W.W. Norton \& Company, 1993, pp. 472-494.

Bitrán Gorén, Yael: “La investigación musical: la experiencia mexicana”, Perspectivas y desafios de la investigación musical en Iberoamerica, Yael Bitrán Gorén, Cynthia Rodríguez Leija (coords.), Ciudad de México, Secretaría de Cultura / Instituto Nacional de Bellas Artes, 2016, pp. 129-144.

Carredano, Consuelo: Ediciones Mexicanas de Música: historia y catálogo, Ciudad de México, Centro Nacional de Investigación, Documentación e Información Musical "Carlos Chávez", 1994.

Corbera Jaume,Amadeu: “Baltasar Samper, compositor: el redescobriment d'un compositor català a l'exili”, Revista Catalana de Musicologia, 11, 2018, pp. 199-231.

Densmore, Francis: Yuman and Yaqui Music, Washington, Smithsonian Institution, Bureau of American Ethnology, 1932.

DíAz Esculías, Daniel: El catalanisme polític a l'exili, Barcelona, La Magrana, 1991.

GAN Quesada, Germán: “La recepció de la música de Robert Gerhard a Catalunya durant el franquisme (1948-1970): trobades i desavinences”, Revista Catalana de Musicologia, 7 , 2014, pp. 153-171.

Grebe, María-Ester: "Primera Conferencia Interamericana de Etnomusicología. Cartagena de Indias, Colombia, 24-28 de Febrero, 1963. Trabajos Presentados”, Journal of the International Folk Music Council, 19, 1967, pp. 142-144.

Hopkins, Nicholas: “The Lacandón Song of the Jaguar". Tlalocan, 15, 2008, pp. 111-113, http://dx.doi.org/10.19130/iifl.tlalocan.2008.184 (consulta 26-12-2020).

Kettler, David: "Spiritual Diaspora and Political Exile", Journal of the Interdisciplinary Crossroads, 1, 2, 2004, pp. 269-282.

LozA, Steven: "Contemporary Ethnomusicology in Mexico", Latin American Music Review / Revista de Música Latinoamericana, 11, 2, 1990, pp. 201-250.

Lumholtz, Carlos: El México desconocido. Cinco años de exploración entre las tribus de Sierra Madre occidental; en la Tierra Caliente de Tepic y Jalisco, y entre los tarasco de Michoacán, Nueva York, Charles Scribner's Sons, 1904. 
MARTí, Josep: "Etnomusicologia catalana: entre la literatura, la musicologia i l'antropologia”, AIXA. Revista Del Museu Etnologic Del Montseny, 4, 1991, pp. 19-34.

—: "Folk Music Studies and Ethnomusicology in Spain", Yearbook for Traditional Music, 29, 1997, pp. 107-140.

Massot i Muntaner, Josep (ed.): Baltasar Samper. Estudis sobre la cançó popular, Barcelona, Publicacions de l'Abadia de Montserrat, 1994.

- (ed.): Obra del Cançoner Popular de Catalunya. Materials. 5. Història de l'Obra del Cançoner i complement a l'inventari de l'arxiu, Barcelona, Publicacions de l'Abadia de Montserrat, 1995.

- (ed.): Obra del Cançoner Popular de Catalunya. Materials. 10. Memòries de missions de recerca per Baltasar Samper; Palmira Jaquetti, Barcelona, Publicacions de l'Abadia de Montserrat, 2000.

—: "Baltasar Samper, de l'Obra del Cançoner a França i a Mèxic", Randa, 82, 2019, pp. 5587.

Moll, Joan: "Conversa d'en Joan Moll amb na Dolors Porta”, X Simpòsium i Jornades Internacionals de l'Orgue Històric de les Balears / Trobada de Documentalistes Musicals, Palma, Fundació ACA, 2003, pp. 123-125.

MeYErs, Helen: "Ethnomusicology", Ethnomusicology. An Introduction, Helen Myers (ed.), Nueva York, W.W. Norton \& Company, pp. 3-18.

PAREYón, Gabriel: Diccionario Enciclopédico de Música en México, Zapopan, Universidad Panamericana, 2007, p. 941.

Ramos López, Pilar: "Musicología española y exilio: continuidades y rupturas", Discursos y prácticas musicales nacionalistas (1900-1970), Pilar Ramos López (ed.), Logroño, Servicio de Publicaciones de la Universidad de La Rioja, 2012, pp. 115-138.

Ruiz Caballero, Antonio: Tras las huellas de Baltasar Samper: influencia de un músico e investigador catalán en la investigación musical mexicana, Barcelona, Institut d'Estudis Catalans, 2015 [inédito: memoria de investigación].

SAID, Edward: Reflections on Exile and Other Literary and Cultural Essays, Londres, Granta Books, 2012.

SAMPer, Baltasar: "La investigación musical en el departamento de música de la SEP", Nuestra Música, 2, 5, 1947, pp. 39-44.

-: "La investigación folklórica en la 'Obra del cancionero popular de Cataluña”, Anuario de la Sociedad Folklórica de México 1945, 6, 1949, pp. 213-232.

- (ed.): Investigación Folklórica en México. Materiales. Volumen I, Ciudad de México, Instituto Nacional de Bellas Artes, 1962.

- (ed.): Investigación Folklórica en México. Materiales. Volumen II, Ciudad de México, Instituto Nacional de Bellas Artes, 1964.

SÁnchez, Rosa Virginia: "La etnomusicología en el CENIDIM a través de los años: una breve revisión”, Cuarenta años de investigación musicológica en México a través del CENIDIM, Yael Bitrán Goren, Luis Antonio Gómez, José Luis Navarro (coords.), Ciudad de México, Instituto Nacional de Bellas Artes, 2016, pp. 149-168. 
El “musicólogo transterrado”. Los escritos etnomusicológicos de Baltasar Samper en México... 269

SÁnchez Cuervo, Antolín: "El exilio como figura política". Líneas de fuga. Hacia otra historiografía del exilio republicano español, Mari Paz Balibrea (coord.), Madrid, Siglo XXI, 2017, pp. 190-195.

Yurchenco, Henrietta:“Grabación de Música Indígena”. Nuestra Música, 1, 1946, pp. 65-79.

-: "Investigación folclórico musical en Nayarit y Jalisco. Grupos indígenas coras y huicholes”, Música y danzas del gran Nayar, Jesús Jáuregui (ed.), Ciudad de México, Centro de Estudios Mexicanos y Contemporáneos, 1993, pp. 141-170.

Recibido: 26-12-2020

Aceptado: 3-6-2021 